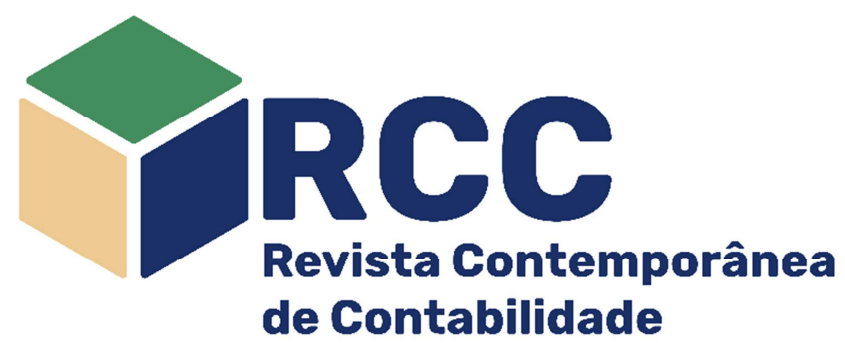

\title{
Relação entre índice de volatilidade implícita e índice de retorno de ações
}

On the relationship between implied volatility index and stock return index

\section{Relación entre el índice de volatilidad implícita y el índice de rentabilidad de las acciones}

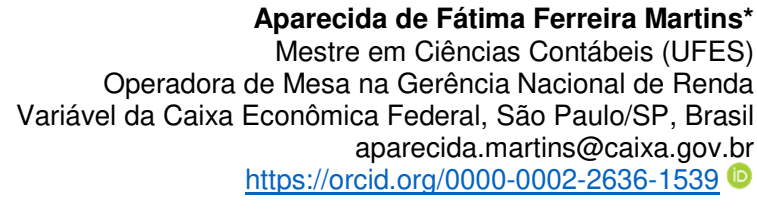

Aparecida de Fátima Ferreira Martins

Mestre em Ciencias Contábeis (UFES) aparg

\author{
Patricia Maria Bortolon \\ Doutora em Administração (COPPEAD/UFRJ) \\ Professora do Programa de Pós-Graduação em Ciências Contábeis \\ (UFES), Vitória/ES, Brasil \\ patricia.bortolon@ufes.br \\ https://orcid.org/0000-0001-8087-3837 \\ Vinicius Mothe Maia \\ Doutor em Administração (PUC-RJ) \\ Professor do Programa de Pós-Graduação em Ciências Contábeis \\ (UFRJ), Rio de janeiro/RJ, Brasil \\ vmaia@facc.ufrj.br \\ https://orcid.org/0000-0001-6156-3104 (1)
}

Endereço do contato principal para correspondência* Av. Paulista, 2300, $11^{\circ}$ andar, CEP: 01310-300, São Paulo/SP, Brasil

\section{Resumo}

O estudo investigou a relação entre os retornos do lbovespa e do índice de volatilidade implícita IVol-BR. Foi analisado se o nível do IVol-BR tem relação com os retornos contemporâneos e futuros do lbovespa. Foram utilizadas regressões por MQO e regressão quantílica para investigar eventuais diferenças nas relações ao longo da distribuição da medida IVol-BR. Para testar a robustez do modelo foi adotada uma proxy alternativa para a volatilidade, estimada a partir do modelo $\operatorname{GARCH}(1,1)$. Foi encontrada uma relação assimétrica na resposta do investidor brasileiro aos diferentes momentos de volatilidade no mercado, sugerindo que retornos negativos do Ibovespa possuem relação mais intensa com o IVol-BR que retornos positivos. Os coeficientes são maiores nos extremos da distribuição do IVol-BR. Tais resultados sugerem que o mercado brasileiro reage de forma mais exacerbada a notícias ruins do que a notícias boas, indo ao encontro das ideias desenvolvidas pelo campo das finanças comportamentais.

Palavras-chave: Índice de volatilidade; IVol-BR; Ibovespa; Finanças comportamentais

\section{Abstract}

This study investigated the relationship between the lbovespa returns and the implied volatility index in Brazil (IVol-BR). We analyzed whether the level of the IVol-BR is related to the present and future lbovespa returns. OLS and quantile regressions were used to investigate possible differences in the relationships along the distribution of the IVol-BR. To test the robustness of the model, we applied an alternative proxy for volatility, estimated from a GARCH $(1,1)$ model. An asymmetrical relationship was found in Brazilian investors' response to different moments of market volatility, suggesting that negative lbovespa returns have a stronger relationship with the IVol-BR than positive returns. The coefficients were higher at the extremes of the IVol-BR distribution. These results suggest that the Brazilian market reacts more strongly to bad news than to good news, in line with the ideas developed in the behavioral finance field.

Keywords: Volatility index; IVol-BR; Ibovespa; Behavioral finance

\section{Resumen}

Este estudio investigó una relación entre los retornos de lbovespa y el índice de volatilidade implícita IVolBR. Foi analisado se o nível do IVol-BR tem relação com os retornos contemporâneos e futuros do Ibovespa. Foram utilizados regressões por MQO e regressão quantílica para investigar eventuais diferenças nas relações ao longo da distribuição da medida IVol-BR. Para testar a robustez do modelo foi adotada uma 
proxy alternativa para a volatilidade, estimada a partir de modelo $\operatorname{GARCH}(1,1)$. Foi encontrada uma relação assimétrica na resposta do investidor brasileiro aos diferentes momentos de volatilidade no mercado, sugerindo que retornos negativos do lbovespa possuem relação mais intensamente com o IVol-BR que retornos positivos. Os coeficientes são maiores nos extremos da distribuição do IVol-BR. Tais resultados sugerem que o mercado brasileiro reage de forma mais exacerbada a notícias ruinas do que a notícias boas, indo ao encontro das ideias desenvolvidas pelo campo das finanças comportamentais.

Palabras clave: Índice de volatilidad; IVol-BR; Ibovespa; Finanzas conductuales

\section{Introdução}

A volatilidade atrai a atenção de acadêmicos e praticantes do mercado, em parte por ser uma variável não observável diretamente no mercado, necessitando ser estimada, (Pinho, Camargos, \& Figueiredo, 2017). Os modelos usados para este fim evoluíram da estimação através do desvio padrão, medida clássica de dispersão estatística, para modelos multivariados, como os modelos da família GARCH (General Autoregressive Condicional Heteroskedasticity), sendo a volatilidade considerada uma medida para a incerteza de um ativo.

A volatilidade também é utilizada no cálculo de medidas de desempenho, como, por exemplo, o Índice de Sharpe, que calcula o trade-off entre recompensa (o prêmio de risco) e o risco, (Bodie, Kane, \& Marcus, 2015). Os participantes do mercado também empregam a volatilidade para o cálculo e precificação de derivativos, como as opções (Mello, 2009). A correta estimação da volatilidade assume grande relevância na precificação dos ativos, assim como na elaboração de estratégias de investimentos (Pinho et al., 2017).

A partir de Engle (1982), o estudo da volatilidade evoluiu para modelos de heterocedasticidade condicional, onde a variância não é constante ao longo do tempo e sim condicional ao passado. Estes são os modelos estatísticos da família ARCH.

As abordagens descritas até aqui são baseadas em dados passados, observando-se as variações dos retornos ao longo de um período. Considerando que comportamentos passados não necessariamente se repetirão no futuro, sua utilização como estimativa para volatilidade futura pode não ser a solução ideal.

Com esse pensamento em mente que a volatilidade implícita foi desenvolvida. Essa medida de volatilidade se baseia na expectativa futura de risco implícito nos prêmios das opções negociadas no mercado. A abordagem mais comum de cálculo da volatilidade implícita é a aplicação da metodologia reversa ao modelo Black-Scholes, ou seja, a partir do preço da opção negociada, a volatilidade implícita é estimada. Como a função inversa não admite solução analítica explícita, utilizam-se métodos numéricos para o cálculo (Mello, 2009).

As medidas de volatilidade implícita têm ganhado espaço na literatura de finanças, principalmente a partir do desenvolvimento do índice de volatilidade implícita do mercado americano, o VIX. Esse índice media inicialmente a expectativa de risco do mercado baseada nas opções no dinheiro do S\&P100. Em 2003, o VIX foi atualizado e o "novo VIX" é baseado no índice S\&P500, o principal índice americano para ações. Ele reflete a dinâmica de duas variáveis, o nível de risco, estimado pela variância futura esperada; e o preço desse risco, que é uma medida da aversão ao risco do investidor (Whaley, 2000).

Essa nova forma de medir a volatilidade, com a especial vantagem de permitir uma estimativa da volatilidade futura, impacta a literatura de finanças em três frentes; (i) uma nova medida de risco pode afetar as decisões de carteira sob a Teoria dos Portfolios de Markowitz (1952); (ii) a Hipótese de Eficiência dos Mercados de Fama (1970) é desafiada uma vez que a volatilidade futura pode ser utilizada na previsão de retornos e estratégias de investimento vencedoras e (iii) a aproximação do campo de finanças ao de psicologia e os desenvolvimentos das Finanças Comportamentais e mais recentemente a Hipótese dos Mercados Adaptativos têm na medida de volatilidade implícita uma métrica que pode ser entendida como uma medida de medo do investidor (Kahnemann e Tversky, 1979; Lo, 2004).

A análise da relação contemporânea do VIX com os retornos introduz o índice como uma proxy para o medo do investidor. Whaley (2000) mostra que o mercado reage mais negativamente a um aumento no VIX do que positivamente quando o VIX cai. Essa assimetria, ou seja, a resposta mais forte do mercado ao aumento da volatilidade, é que justifica o VIX ser entendido como uma proxy para o medo do investidor. O campo de estudo das finanças comportamentais explica esse movimento, mostrando que o investidor reage de forma mais exacerbada à uma informação ruim do que a uma informação boa. Assim, quando a volatilidade esperada do mercado aumenta, investidores entendem como uma informação negativa e demandam uma taxa de retorno maior fazendo com que os preços das ações caiam. O movimento não acontece com a mesma intensidade quando a volatilidade diminui (informação boa). Smales (2016) mostra que o relacionamento entre as mudanças no nível de medo do investidor e os retornos do mercado financeiro sugere um movimento consistente com a fuga para qualidade à medida que o medo aumenta (fly to quality').

Giot (2005) destaca o pouco foco das pesquisas na possível relação entre volatilidade implícita e retorno futuro de ações, o que o autor atribui a crença de que os mercados são eficientes. Banerjee, Doran 
e Peterson (2007) encontraram evidências de que o VIX possui forte capacidade preditiva do retorno dos portfólios. Smales (2016) também identifica a capacidade preditiva, mas para níveis extremos de medo do investidor. Giot (2005) analisa relações contemporâneas e futuras, dos índices VIX e VXN, baseados respectivamente nos índices de mercado S\&P500 e Nasdaq100. O autor conclui que há uma relação forte e negativa entre mudanças nos índices de volatilidade implícita e os índices de retornos de ações investigados.

No cenário brasileiro, pesquisadores da Universidade de São Paulo (USP) desenvolveram um índice de volatilidade implícita baseado no VIX para o mercado brasileiro, chamado de "IVol-BR". Esse índice se baseia no VIX, e adota ajustes que levam em conta a baixa liquidez do mercado brasileiro. O IVolBR é baseado nos preços diários das opções sobre o índice lbovespa, vencíveis em 2 meses.

Vicente e Guedes (2010) estudaram a informatividade da volatilidade implícita sobre a volatilidade futura, utilizando dados de ações da Petrobras de janeiro de 2006 a dezembro de 2008. Os autores concluíram que a volatilidade implícita das opções ITM (in the money) não é relevante para explicar volatilidade realizada, já a volatilidade implícita das opções ATM (at the money) contém informação sobre a volatilidade futura, embora possua viés. Os autores estimam que a diferença entre volatilidade implícita e volatilidade realizada pode ser devida ao prêmio de risco exigido pelos investidores, mostrando que opções são usadas como hedge em ambientes arriscados.

Mello (2009) estudou a capacidade de previsão do mercado sobre a volatilidade futura, buscando identificar o melhor preditor para volatilidade futura, comparando modelos de média móvel e GARCH com a volatilidade implícita. Foram encontradas evidências de que a volatilidade implícita possui informação da volatilidade realizada, porém ambos os estimadores testados se mostraram enviesados. Os resultados sugerem que o mercado sobrestima a volatilidade futura, sendo justificável pelo fato de que as opções são, de alguma forma, um porto seguro e, naturalmente, os agentes estariam dispostos a pagar um prêmio pelo seu "valor justo" pelo fato de haver eventos os quais eles não conseguem prever para indexar ao preço das opções, conhecidos como "Black Swan",ii (Taleb, 2010).

Dados os achados das pesquisas realizadas no campo da volatilidade e das finanças comportamentais, relacionando volatilidade implícita e retorno de mercado, além de volatilidade e o comportamento do investidor, este estudo busca investigar o seguinte: Existe relação entre a volatilidade implícita, medida pelo IVol-BR, e os retornos do lbovespa?

Ao responder à pergunta de pesquisa, dois objetivos são alcançados. O primeiro é, ao analisar a relação contemporânea entre o IVol-BR e os retornos do Ibovespa, verificar a utilidade do IVol-BR como "índice de medo" do mercado brasileiro. De acordo com Giot (2005), o VIX pode ser considerado o "índice do medo", já que o mercado americano cai mais quando há aumento na volatilidade implícita, e a reação quando há queda não é proporcional. O segundo objetivo é verificar se a volatilidade implícita possui alguma relação com os retornos futuros do mercado. De acordo com Giot (2005), os participantes de mercado têm o raciocínio de que, em períodos de alta volatilidade implícita, investidores exageram, então vendem ativos de forma indiscriminada para levantar dinheiro ou limitar perdas, deixando os ativos baratos, daí surge o estudo da possível relação entre volatilidade implícita e o retorno futuro do mercado.

Este artigo se aproxima do trabalho de Cainelli, Pinto e Klotzle (2021) que também investigaram a relação entre o IVol-BR e os retornos do Ibovespa. Entretanto, há diferenças metodológicas relevantes: (i) os autores focam na relação entre o IVol-BR e os retornos futuros e não exploram a relação entre o IVol-BR e os retornos contemporâneos do Ibovespa conforme Giot (2005) sugere e adotamos neste estudo. Neste estudo o IVol-BR é a variável dependente, como em Giot (2005) e em Cainelli et al. (2021) o mesmo é variável explicativa; (ii) os autores focam sua análise nos extremos da distribuição do IVol-BR, enquanto nosso estudo investiga possíveis diferentes relações ao longo de toda a distribuição do índice, de duas formas distintas, com percentis pré-definidos e através de regressão quantílica, possível uma vez que aqui o IVol-BR é variável dependente; (iii) os autores utilizam interpolação nas datas sem IVol-BR, procedimento que evitamos por entender que altera as médias e demais estatísticas da série real observada; (iv) o período de análise aqui é mais longo, terminando em abril/2019. O presente estudo, portanto, complementa os achados do artigo mencionado em aspectos que apresentamos na seção de análise dos resultados.

Como contribuição acadêmica, pode-se considerar o fato de o estudo relacionar o IVol-BR aos retornos do lbovespa contribuindo para a validação do índice desenvolvido para o mercado brasileiro, o qual não possui métrica oficial para a volatilidade implícita. Metodologicamente, o trabalho contribui de duas formas: (i) testando diferentes métricas para a volatilidade, uma vez que usa o IVol-BR para estimar a volatilidade implícita e o modelo GARCH como alternativa; (ii) e diferentes métodos de estimação, incluindo a regressão quantílica.

Como contribuição prática, o trabalho apresenta uma nova forma de entender a relação entre risco e retorno no mercado brasileiro, podendo auxiliar gestores no momento de estruturar sua metodologia de investimento. Ao identificar um possível comportamento assimétrico do mercado os gestores podem melhorar sua metodologia de estruturação de carteiras, antecipando seus movimentos e obtendo rentabilidades acima da média com melhores timings de entradas e saídas de posições. 


\section{Revisão de Literatura e Desenvolvimento de Hipóteses}

De acordo com a teoria de carteiras de Markowitz (1952) as escolhas de ativos e carteiras dependem das crenças a respeito do desempenho futuro do ativo (retornos esperados) e a variância esperada desse retorno. O investidor busca os maiores retornos com os menores riscos e leva em consideração a covariância entre os ativos de forma a minimizar o risco da carteira. Dados sobre retornos futuros, e mais ainda variâncias e covariâncias futuras, são um desafio à tomada de decisão. Estudos sobre volatilidade e formas de entender seu comportamento assumem papel relevante na literatura de finanças.

Todo o esforço de análise dessas variáveis com objetivo de obter retornos anormais é questionada por Fama (1970) e sua Hipótese dos Mercados Eficientes (HME). Em um mercado eficiente os preços refletem completamente toda a informação disponível, e não há possibilidade de ganhos anormais. $\mathrm{A}$ eficiência de mercado pode se dar de três formas distintas: fraca, semiforte e forte. Na forma fraca os preços incorporam todas as informações passadas, na semiforte são incorporadas também todas as informações públicas disponíveis. A eficiência na forma forte significa que os preços refletem todas as informações disponíveis, sejam elas públicas ou não.

O desenvolvimento teórico sobre a análise e tomada de decisão em condições de incerteza, baseado na teoria da utilidade e decisões racionais, desenvolvido por Friedman e Savage (1948) passa a ser questionado a partir de estudos que aliam psicologia comportamental às finanças na década de 70 . Kahneman e Tversky (1979) é um marco nessa literatura, apresentando a Teoria dos Prospectos. Os autores mostram evidências de que os tomadores de decisão apresentam vieses cognitivos incompatíveis com as escolhas racionais e a correta avaliação de probabilidades e informações. Na Teoria dos Prospectos o valor é atribuído aos ganhos e perdas e não aos ativos finais. A função valor mostra que a aversão ao risco é maior no campo das perdas do que nos ganhos.

A tomada de decisão quando há perdas ou crises é objeto de investigação na literatura sobre finanças comportamentais. Imas (2016) menciona os resultados contraditórios na literatura, onde estudos mostram uma maior tomada de risco após perdas, e outros uma menor tomada de risco. $\mathrm{O}$ autor reconcilia os resultados mostrando que quando a perda é realizada, o indivíduo evita o risco, mas quando essa perda não é realizada ele fica propenso a tomar mais risco. Já Guiso et al. (2018) mostram que, após crises, a aversão ao risco aumenta significativamente. Os autores mostram também que indivíduos que experimentam um aumento grande na aversão ao risco após crises, têm quatro vezes mais chances de vender ações durante o pior momento da crise do que indivíduos que não têm esse aumento na aversão ao risco.

Se a psicologia é associada às finanças no desenvolvimento de um novo campo de estudos, Lo (2004) traz conceitos da sociologia e da biologia evolutiva para a investigação das controvérsias sobre a HME. O autor apresenta a Hipótese dos Mercados Adaptáveis (HMA). Segundo ele a eficiência de mercado não pode ser avaliada em um vácuo, uma vez que é dependente de um contexto dinâmico. Esse contexto dinâmico é semelhante ao aumento e diminuição de uma população de insetos, por exemplo, que é função de sazonalidades, predadores e de sua capacidade de adaptação. Os preços refletem uma combinação de condições ambientais e da natureza das "espécies" na economia. As espécies são os distintos participantes do mercado, cada um com comportamentos característicos. Todos competem por recursos escassos. Segundo o autor, sob estas lentes de análise, é possível entender as aparentes contradições entre a HME e a presença e persistência de vieses comportamentais.

Sob a HMA, a inovação é a chave para sobrevivência. A HMA sugere que, para atingir retornos consistentes é necessário adaptar a estratégia às mudanças nas condições de mercado, o que envolve uma multiplicidade de habilidades. Gestores de investimentos, por exemplo, seriam uma espécie menos propensa a extinção do que investidores pessoa física. Isso traz uma implicação clara para todos os participantes dos mercados financeiros: sobrevivência é o único objetivo que importa (Lo, 2004).

Os estudos sobre risco e volatilidade em suas mais diversas medidas se inserem nesse contexto de evolução nos estudos sobre finanças. As medidas de volatilidade vão desde uma medida de dispersão dos dados em torno da média aritmética, como o desvio padrão, até modelos de médias móveis, que permitem uma melhor avaliação do movimento nos dados ao longo do tempo e da existência ou não de alguma tendência de longo prazo na série (Levine et al., 2016). A abordagem das médias móveis pode ser implementada também por modelos de médias móveis ponderadas, onde pesos diferentes podem ser atribuídos às diferentes defasagens, e modelo de alisamento exponencial, onde a previsão é feita através da média exponencialmente ponderada de observações anteriores.

A análise da volatilidade histórica evoluiu para os modelos $A R C H$ e $\mathrm{GARCH}$, propostos por Engle (1982). Esses modelos permitem analisar a existência de clusters de volatilidade, ou seja, a tendência de períodos de alta volatilidade serem condicionais a períodos de, também, alta volatilidade. Os modelos permitem que a variância condicional mude ao longo do tempo. No modelo $\mathrm{ARCH}$ a variância do erro está relacionada com o termo de erro elevado ao quadrado no período anterior, e no modelo GARCH essa relação ocorre com os termos de erro elevados ao quadrado em vários períodos anteriores. 
Todas as medidas anteriores analisam dados passados, entretanto, os modelos de decisão do investidor das teorias de finanças discutidas anteriormente, demandam estimativas de valores esperados. As medidas de volatilidade implícita apresentadas a seguir são desenvolvimentos nesse sentido.

O VIX é o índice de volatilidade implícita do mercado americano e expressa o consenso dos investidores a respeito da volatilidade futura esperada para o mercado de opções. O índice é baseado no índice S\&P500, o principal índice americano para ações. Ele reflete a dinâmica entre o nível de risco e o preço desse risco, que é uma medida da aversão ao risco do investidor. O cálculo parte do modelo de valuation do índice de opções de ações que tem todos os parâmetros exceto um, conhecidos ou passíveis de estimação com acurácia. O parâmetro desconhecido seria a volatilidade implícita.

A fórmula geral de cálculo do VIX é a que segue:

$$
\begin{gathered}
\sigma^{2}=\frac{2}{T} \sum_{i} \frac{\Delta \mathrm{K}_{i}}{K_{i}^{2}} e^{R T} Q\left(K_{i}\right)-\frac{1}{T}\left[\frac{F}{K_{0}}-1\right]^{2} \\
\text { Equaçãa 1 - Cálculo do VIX }
\end{gathered}
$$

Onde: iii

$\sigma=\frac{V I X}{100} \rightarrow \mathrm{VIX}=\sigma \times 100$

$T=$ Tempo para o vencimento da opção

$F=$ Nível do índice de futuro derivado do índice de preço de opções

$K_{0}=$ Primeiro preço abaixo do índice futuro $\mathrm{F}$

$K_{i}=$ Preço de exercício de uma opção out-of-money, uma call se $K_{i}>K_{0}$, e uma put se $K_{i}<K_{0}$, ou, ainda, put e call se $K_{i}=K_{0}$

$\Delta K_{i}=$ Intervalo entre os preços de opções - metade da diferença entre o preço de qualquer lado de $K_{i}$ :

$R=$ Taxa de juros livre de risco

$$
\Delta K_{i}=\frac{K_{i+1}-K_{i-1}}{2}
$$

$Q K_{i}=$ Ponto médio do bid-ask spread para cada opção com preço $K_{i}$

A medida de volatilidade implícita é objeto de diversos estudos com os focos concentrando-se em utilizá-la como possível preditor da volatilidade e como nova medida de risco a ser relacionada a retornos contemporâneos e futuros.

Para Giot (2005), deve-se comparar a crença de que a volatilidade implícita não teria nenhuma relação com preços das ações, derivada da Teoria dos Mercados Eficientes (TME), com as opiniões de participantes do mercado, para os quais níveis altos de volatilidade implícita são vistos como sinalizadores para investidores em posições compradas. Segundo o autor, o raciocínio dos participantes do mercado seria da seguinte forma: em períodos de alta volatilidade implícita, os investidores estão exagerando, vendendo ativos financeiros indiscriminadamente para levantar dinheiro ou limitar perdas, o que deixaria os ativos baratos. Essa reação é coerente com achados de Imas (2016) e Guiso et al. (2018) e também encontra suporte na HMA, quando relaciona com sobrevivência a permanência num mercado ou a saída dele, mostrando que os investidores que não sobrevivem são estes que reagem de forma exagerada e acabam eliminados do "ecossistema" do mercado financeiro.

Giot (2005) verificou a relação entre o índice de volatilidade implícita do mercado americano e o índice de retorno de ações S\&P100. O autor encontrou evidências de um relacionamento forte e negativo entre mudanças contemporâneas nos índices de volatilidade implícita e os índices de ações utilizados no trabalho, além de verificar a existência da relação entre retorno futuro positivo e índices de volatilidade implícita extremamente altos. Para verificar se níveis altos de volatilidade implícita são sinais relevantes para posições compradas, o autor usa um algoritmo que classifica os níveis de volatilidade implícita em 20 percentis igualmente espaçados, depois ele ranqueia os percentis para uma classificação de volatilidade implícita alta ou baixa. O índice de volatilidade implícita alto estaria próximo do percentil 15 ou acima deste, o índice de volatilidade implícita muito alto estaria próximo do percentil 20. Ou seja, Giot (2005) mostra que há alguma evidência de que retornos futuros positivos são esperados em posições compradas em períodos de volatilidade implícita alta, mas, para que isso se torne atrativo, a volatilidade implícita deve ser extremamente alta. Os achados desafiam a HME e tem explicações na literatura sobre finanças comportamentais.

Rubbaniy et al. (2014) investigam o poder preditivo de três índices de volatilidade implícita sobre os retornos futuros de índices de ações. O estudo usa dados diários de 1990 a 2009 dos índices S\&P500, NASDAQ 100 e DAX 20, e seus índices de volatilidade implícita VIX, VXN e VDAX. Os autores também exploram essa relação durante a crise financeira de 2008 e sob períodos mais recentes de mercados em alta (bull market - julho de 2002 a setembro de 2007) e mercados em baixa (bear market - outubro de 2007 a dezembro de 2009). Seus achados sugerem que os índices de volatilidade implícita têm capacidade 
preditiva para retornos futuros de 20 e 60 dias, mas não para 1 e 5 dias. Ao analisar os diferentes níveis de volatilidade, seus resultados são coerentes com os de Giot (2005), mostrando que altos níveis de volatilidade implícita coincidem com retornos positivos futuros nos índices. Também regrediram os índices de volatilidade com retornos de um portfólio caracterizado pelo beta, tamanho e book-to-market, e testaram se a volatilidade implícita ainda está apta para prever retornos futuros quando outros fatores de risco estão envolvidos. O VXN e VDAX apresentaram resultados um pouco contraditórios o que torna mais difícil uma conclusão generalista. Existem várias razões que podem explicar essas diferenças, como liquidez, tamanho, diversidade das firmas listadas no mercado etc.

Rubbaniy et al. (2014) acreditam que índices de volatilidade implícita podem ser usados para antecipar a direção do mercado e que são boas ferramentas analíticas para identificar oportunidades de entradas e saídas. Além disso, acreditam que existem outros movimentos de mercado que não estão refletidos nos índices de volatilidade, sendo estes insuficientes para prever o desempenho futuro do mercado. Outros fatores devem ser considerados quando se prevê retorno futuro. Estratégias de investimentos baseadas na habilidade preditiva de índices de volatilidade implícita devem ser combinadas com outros indicadores de timing de mercado.

Bagchi (2012) faz um estudo para preencher a lacuna de pesquisa sobre volatilidade implícita em mercados emergentes. Seu estudo avalia o relacionamento entre o VIX da Índia e 3 parâmetros: beta da ação, market-to-book e capitalização de mercado. Seus resultados mostram que o VIX da Índia tem um relacionamento positivo e significante com os retornos dos portfólios montados para 30 e 45 dias futuros. Coerente com os estudos citados anteriormente o VIX indiano pode representar ferramenta de predição do mercado para traders e investidores.

Lee (2015) estudou as relações entre o VIX e os índices de volatilidade implícita de países emergentes, como Índia, Coreia do Sul, África do Sul e Rússia. O autor encontrou evidências de que mudanças no VIX impactam as mudanças nos índices de volatilidade implícita dos mercados emergentes.

$\mathrm{Li}$, Yu e Luo (2019) estudaram a relação entre índice de volatilidade e retornos com dados intradiários do mercado de opções Chinês. O objetivo foi identificar se o índice de volatilidade do mercado de opções da China, o iVX, poderia ser usado como uma proxy do medo do mercado, como o VIX no mercado americano. As evidências encontradas demonstram que o iVX pode ser utilizado como proxy de medo do mercado quando há grandes mudanças, além de ter concluído que há uma relação assimétrica entre os retornos de mercado e o iVX.

No mercado brasileiro o índice de volatilidade implícita é calculado pelo Núcleo de Estudos em Finanças da USP (NEFIN). O IVol-BR se baseia nos mesmos fatores do VIX, combinando a metodologia internacional padrão usada em mercados de alta liquidez com ajustes que levam em conta a baixa liquidez e a baixa quantidade de exercício de opções do mercado brasileiro. O índice é baseado nos preços diários das opções sobre o lbovespa, considerando um horizonte de 2 meses, acompanhando o vencimento das opções.

De acordo com Astorino et al. (2017), um índice de volatilidade implícita deve refletir a dinâmica do nível do risco que o investidor encontra - a volatilidade futura esperada - e o preço desse risco - a aversão ao risco dos investidores. Dado isso, o IVol-BR deveria ser mais alto em períodos de estresse, corroborando com o estudo de Whaley (2000) e sendo um parâmetro do medo do investidor brasileiro quanto à queda do mercado.

De acordo com Pinho, Camargos e Figueiredo (2017) entre os anos de 2000 e 2014, nas revistas classificadas pelo Qualis-CAPES como A2, B1 e B2, foram publicados 51 artigos com tema relacionado à volatilidade. Sobre volatilidade implícita, a literatura nacional é ainda mais carente de estudos, tendo sido utilizado para o cálculo da volatilidade, em artigos nacionais, apenas três vezes, entre 2000 e 2014 . Nos períodos posteriores ao estudado por eles, continuamos a ver poucos artigos sendo produzidos sobre a relação entre volatilidade implícita e retornos.

O estudo de Mello (2009), testou modelos para predição de volatilidade futura e verificou que a volatilidade implícita possui informação da volatilidade realizada, porém ambos os estimadores utilizados se mostraram enviesados.

Vicente e Guedes (2010) verificaram se a volatilidade implícita possui informação sobre a volatilidade futura, utilizando como amostra ações da Petrobras de 2006 a 2008. Concluíram que, apesar de a volatilidade implícita das opções ATM possuir informação sobre a volatilidade futura, o estimador também é enviesado.

Cainelli et al. (2021) analisam a relação entre o IVol-BR e os retornos futuros do lbovespa e mostram a capacidade preditiva do índice principalmente para retornos de 20, 60, 120 e 250 dias a frente, sendo pouco explicativo dos retornos de 1 e 5 dias.

Baseado nos trabalhos internacionais e nacionais revisados, o presente estudo busca verificar as seguintes hipóteses:

H1: Existe relação empírica entre o IVol-BR e o índice de retorno de ações Ibovespa.

Essa hipótese busca verificar se, assim como encontrado por Giot (2005), o índice de ações Ibovespa é, de alguma forma, relacionado com o IVol-BR.

\section{H2: O IVol-BR possui relação com o retorno futuro do índice lbovespa.}


Neste caso, o objetivo é tentar verificar se, o retorno futuro do lbovespa possui relação com o IVolBR. Caso a hipótese seja confirmada, pode ser verificada a relação entre volatilidade implícita e retorno mercado, relação esta que não deveria ser confirmada caso o mercado brasileiro se comportasse na forma forte de eficiência de mercado.

\section{Metodologia}

A amostra inclui dados diários do IVol-BR e do lbovespa no período de 1 de agosto de 2011 a 30 de abril de 2019. A adoção do período estipulado acima se deu devido à disponibilidade dos dados do IVol-BR, que só possui divulgação a partir desta data.

Os dados do Ibovespa foram retirados da base Comdinheiro e os dados do IVol-BR foram retirados do site do NEFIN. Os dados do IVol-BR não estavam disponíveis para todos os dias da amostra, então, os dias em que não havia informações sobre o IVol-BR foram excluídos. A amostra final terminou com um total de 1622 cotações dos índices.

O presente trabalho se propõe a verificar duas relações, quais sejam:

1. O relacionamento contemporâneo entre as mudanças relativas na volatilidade implícita e o retorno das ações;

2. A possível relação entre volatilidade implícita e o retorno futuro do mercado.

Para a primeira análise, foram observadas as mudanças simultâneas no IVol-BR, e no Ibovespa, a partir dos dados diários dos índices. Giot (2005) encontrou relação negativa e estatisticamente significante entre os retornos dos índices de ações e os índices de volatilidade implícita utilizados em seu trabalho, corroborando com os achados de Whaley (2000). Giot (2005) observa que retornos positivos nos índices de ações são associados com o declínio nos níveis de volatilidade implícita, enquanto retornos negativos são associados com o aumento no nível de volatilidade implícita.

$\mathrm{Na}$ segunda análise, o foco se volta para o possível relacionamento entre volatilidade implícita e retorno futuro dos índices de ações. Neste caso, busca-se investigar se níveis altos de volatilidade implícita podem indicar um mercado sobrevendido podendo ser visto, portanto, como sinal para compra nos curto e médio prazos. A metodologia utilizada neste caso será semelhante à utilizada por Campbell e Shiller (1998), que estudaram o link entre o índice preço/lucro observado e o retorno futuro dos índices de ações.

A amostra final para análise das hipóteses possui 1621 retornos para cada índice, perdendo apenas 1 observação dado o cálculo do retorno dos índices utilizados.

Para a hipótese 1, onde será estimada a relação contemporânea entre as variações diárias no $\mathrm{IVol}-\mathrm{BR}_{t}$ e no lbovespa, a equação da regressão se dá pelo que segue:

$$
r_{\text {IVol-BR,t }}=\beta_{0} D_{t}^{+}+\beta_{1} D_{t}^{-}+\beta_{2} r_{\text {Ibovespa, },} D_{t}^{+}+\beta_{3} r_{\text {Ibovespa }, t} D_{t}^{-}+\varepsilon_{t}
$$

Onde:

- $r_{I V o l-B R, t}=\ln \left(I V o l-B R_{t}\right)-\ln \left(I V o l-B R_{t-1}\right)$ que é a mudança diária no nível do índice de volatilidade implícita.

- $r_{\text {Ibovespa,t }}=\ln \left(\right.$ Ibovespa $\left._{t}\right)-\ln \left(\right.$ Ibovespa $\left._{t-1}\right)$, que é o retorno de um dia no índice lbovespa.

- $D_{t}^{-}=$variável dummy que é igual a 1 (0) quando $r_{\text {Ibovespa,t }}$ é negativo (positivo) e

- $D_{t}^{+}=1-D_{t}^{-}$

Para a análise dos coeficientes $\beta_{2}$ e $\beta_{3}$, será observado o valor absoluto dos mesmos. Espera-se que $\beta_{3}$ seja maior que $\beta_{2}$, quando se verificará que retornos negativos do índice lbovespa são associados a maiores mudanças no IVol-BR do que os retornos positivos, de acordo com o encontrado por Giot (2005).

Também foi feito teste com a adição dos termos quadráticos à regressão anterior para capturar o efeito tamanho dos retornos:

$$
\begin{gathered}
r_{I V o l-B R, t}=\beta_{0} D_{t}^{+}+\beta_{1} D_{t}^{-}+\beta_{2} r_{I b o v e s p a, t} D_{t}^{+}+\beta_{3} r_{\text {Ibovespa }, t} D_{t}^{-}+\beta_{4} r_{\text {Ibovespa }, t} D_{t}^{+} \\
+\beta_{5} r^{2}{ }_{\text {Ibovespa }, t} D_{t}^{-}+\varepsilon_{t}
\end{gathered}
$$

Considerando os achados de Giot (2005), o objetivo aqui é verificar se retornos altos ou baixos do índice de ações se movem de forma diferente, considerando mudanças de 1 dia no índice de volatilidade implícita. Giot (2005) encontrou significância estatística pequena para os coeficientes dos termos quadráticos de seus modelos, indicando que, apesar de existir um efeito assimétrico, não existe efeito tamanho.

Considerando a hipótese 2, o objetivo é verificar se o índice de volatilidade implícita pode indicar um mercado sobrevendido ou sobrecomprado. Giot (2005) analisa a questão olhando o relacionamento entre a variação no índice de volatilidade implícita no tempo te o retorno futuro do índice de ações, em 1, 5, 20 e 60 dias úteis à frente.

Na pesquisa, foi adotada metodologia semelhante a utilizada por Giot (2005), logo, foi observado o relacionamento entre o índice de volatilidade implícita IVol-BR e $r_{1} d_{t}, r_{5} d_{t}, r_{20} d_{t}$ e $r_{60} d_{t}$, onde $r_{1} d_{t}, r_{5} d_{t}$, $r_{20} d_{t}$ e $r_{60} d_{t}$ são os retornos futuros do lbovespa nos períodos de 1, $5^{\mathrm{iv}}, 20$ e 60 dias úteis. Giot (2005) busca identificar se níveis muito altos de volatilidade implícita são sinais de negociação relevantes para 
posições compradas e, para isso, utiliza um algoritmo baseado na metodologia de Campbell e Shiller (1998) que classifica os níveis de volatilidade implícita de acordo com 20 percentis igualmente espaçados. Dessa forma, se consegue sair de uma visão qualitativa dos dados para uma visão quantitativa do ambiente de negociação, possibilitando ordenar os níveis observados do índice de volatilidade implícita.

Em seu estudo, Giot (2005) utiliza um período de 2 anos para estabelecer os percentis do índice de volatilidade implícita e a partir daí relacioná-lo com o índice de retorno de ações. No presente trabalho foi feita uma adaptação à metodologia utilizada por Giot e por Campbell e Shiller, então a distribuição do índice foi analisada no período de 1 ano anterior ao momento t e, ao invés de classificar em 20 percentis. Foram identificadas por uma variável dummy as observações 30\% menores e as observações 30\% maiores, objetivando identificar a influência de níveis baixos e altos da volatilidade implícita no retorno do lbovespa.

Para avaliar a Hipótese 2 deste trabalho, foram estimadas regressões conforme segue:

$$
\begin{aligned}
& r 1 d_{t}=\beta_{0}+\beta_{1} \text { Dmenor }_{t}+\beta_{2} \text { Dmaior }_{t}+\varepsilon_{t} \\
& r 5 d_{t}=\beta_{0}+\beta_{1} \text { Dmenor }_{t}+\beta_{2} \text { Dmaior }_{t}+\varepsilon_{t} \\
& r 20 d_{t}=\beta_{0}+\beta_{1} \text { Dmenor }_{t}+\beta_{2} \text { Dmaior }_{t}+\varepsilon_{t} \\
& r 60 d_{t}=\beta_{0}+\beta_{1} \text { Dmenor }_{t}+\beta_{2} \text { Dmaior }_{t}+\varepsilon_{t}
\end{aligned}
$$

Em seu trabalho, Giot (2005) verifica que a maioria dos coeficientes da área central do ranking não são significantes, que os nas posições mais altas do ranking são fortemente e positivamente significantes e que os coeficientes nas posições mais baixas do ranking são fortemente e negativamente significantes. Estes resultados suportam a hipótese de que níveis altíssimos de volatilidade implícita sinalizam um bom momento de entrada para posições compradas do referido índice. $O$ autor verifica que isso é consistente com as conclusões dos participantes de mercado de que mercados altamente voláteis são sobrevendidos, 0 que deve beneficiar participantes que entram em posições compradas.

A amostra final dessa análise possui 1369 observações, dada a perda de 252 observações que foram usadas para construção do ranking inicial para agregar em clusters de acordo com o grupo.

Adicionalmente, a volatilidade foi estimada pelo modelo $\operatorname{GARCH}(1,1)$, substituindo o IVol-BR nas análises anteriores, sendo aplicados ao GARCH os mesmos métodos aplicados para o IVol-BR. Essa análise permitiu uma comparação dos resultados encontrados a partir do IVol-BR com um modelo clássico, assim como feito por Duppati, Kumar, Scrimgeour e Li (2017), e funcionou como um teste de robustez.

Considerando a volatilidade estimada por $\operatorname{GARCH}(1,1)$ se dar em base diária e a volatilidade dada pelo IVol-BR se dar em base anual, a volatilidade calculada por GARCH foi anualizada para ficar na mesma base. Além disso, há outra diferença na estimação das métricas pelo IVol-BR e GARCH $(1,1)$, qual seja: para o modelo GARCH $(1,1)$, a estimação se dá para um dia à frente da observação do preço no dia anterior e, para o IVol-BR, a estimação é feita com base em opções que tem prazo de vencimento em 21 dias à frente.

O trabalho de Giot (2005) observou que em níveis muito altos ou níveis muito baixos de volatilidade, a relação com o índice de retorno de ações se dá de forma diferente, por isso, para avaliar o possível efeito entre IVol-BR e o lbovespa, em diferentes níveis de volatilidade, foi aplicado o método de regressão quantílica. Esse método de estimação é empregado quando a relação entre a variável dependente e as variáveis independentes não é constante ao longo da distribuição da variável dependente, dessa forma a relação média captada pela regressão tradicional (Mínimo Quadrados Ordinários) não seria capaz de explicar o fenômeno analisado (Angrist \& Pischke, 2009). Em virtude do efeito alavancagem, amplamente estudado na literatura, é esperado que a relação entre a volatilidade e o retorno não seja a mesma para diferentes níveis de volatilidade (Thurner, Farmer \& Geanakoplos, 2012). A mesma metodologia foi aplicada à volatilidade medida pelo modelo GARCH $(1,1)$.

\section{Resultados e Análises}

A tabela 1 apresenta a estatística descritiva dos dados. Observando a Tabela 1 é possível verificar que os dados possuem distribuição leptocúrtica e que os retornos do IVol-BR possuem assimetria à esquerda, enquanto os retornos do lbovespa e os retornos medidos pelo modelo GARCH possuem assimetria à direita.

Foram feitos testes de estacionariedade das séries de retornos do IVol-BR, da volatilidade estimada pelo modelo GARCH e do lbovespa, através dos testes de Dickey-Fuller Aumentado, teste de raiz unitária de Phillips-Perron e teste Kwiatkowski-Phillips-Schmidt-Shin (KPSS). Para todas as variáveis, os testes utilizados indicam que as séries são estacionárias ao nível de significância de 0,01, não havendo problema de raiz unitária. 
Tabela 1

Estatística descritiva dos dados

\begin{tabular}{lc} 
& $\begin{array}{c}\text { Total } \\
(\mathbf{n}=1621)\end{array}$ \\
\hline Retorno Ibovespa & \\
Média (Desvio Padrão) & $0.000353(0.0147)$ \\
Mediana [Min, Max] & $1.51 \mathrm{e}-05[-0.0499,0.0639]$ \\
Curtose & 0.6273177 \\
Assimetria & 0.1439438 \\
$\quad$ Retorno IVol-BR & $5.23 e-05(0.116)$ \\
Média (Desvio Padrão) & $-0.00120[-0.637,0.484]$ \\
Mediana [Min, Max] & 2.622028 \\
Curtose & -0.1267248 \\
Assimetria & \\
Retorno GARCH & $0.000123(0.0668)$ \\
Média (Desvio Padrão) & $-0.0188[-0.218,0.801]$ \\
Mediana [Min, Max] & 29.12025 \\
Curtose & 3.772893 \\
Assimetria &
\end{tabular}

Fonte: Elaboração própria.

A análise de correlação entre as variáveis utilizadas serve para identificar a intensidade da relação entre elas, podendo sugerir problemas de multicolinearidade. Analisando a correlação entre os dados, foi verificada uma correlação negativa entre o retorno do lbovespa e os retornos do IVol-BR, o que sugere uma relação inversa entre as variáveis. Quanto à volatilidade medida pelo modelo $\mathrm{GARCH}$, a correlação encontrada foi positiva. Quando se trata de retornos futuros, todos os retornos futuros do lbovespa possuem correlação negativa com o IVol-BR, enquanto com os retornos da volatilidade medida pelo modelo GARCH, apenas os retornos futuros de 1 dia e os de 20 dias apresentam essa correlação negativav.

Com a finalidade de testar a H1, foi estimado o modelo de regressão de acordo com as equações (1) e (2), utilizando abordagem de MQO (Mínimos Quadrados Ordinários). Os resultados dos modelos estimados com erro padrão robusto entre parêntesis são apresentados na Tabela 2.

Tabela 2

Resultados do modelo da equação (1) e (2) para IVol-BR

\begin{tabular}{|c|c|c|}
\hline & \multicolumn{2}{|c|}{ Variável Dependente } \\
\hline & \multicolumn{2}{|c|}{$\mathrm{r}_{\mathrm{IVol}-\mathrm{BR}}$} \\
\hline \multirow[t]{2}{*}{$\mathrm{D}_{\mathrm{t}}^{+}$} & $-0.020^{\star \star \star}$ & -0.002 \\
\hline & $(0.006)$ & $(0.008)$ \\
\hline \multirow[t]{2}{*}{$\mathrm{D}_{\mathrm{t}}^{-}$} & -0.007 & -0.004 \\
\hline & $(0.006)$ & $(0.008)$ \\
\hline \multirow[t]{2}{*}{$\mathrm{r}_{\text {Ibovespa,t }} \mathrm{D}_{\mathrm{t}}^{+}$} & 0.532 & $-2.808^{* \star *}$ \\
\hline & $(0.413)$ & $(1.076)$ \\
\hline \multirow[t]{2}{*}{$\mathrm{r}_{\text {Ibovespa,t }} \mathrm{D}_{\mathrm{t}}^{-}$} & $-1.854^{* * *}$ & -1.216 \\
\hline & $(0.449)$ & $(1.249)$ \\
\hline \multirow[t]{2}{*}{$\mathrm{r}_{\text {Ibovespa,t }}^{2} \mathrm{D}_{\mathrm{t}}^{+}$} & & 19.693 \\
\hline & & $(35.990)$ \\
\hline \multirow[t]{2}{*}{$\mathrm{r}_{\text {Ibovespa,t }}^{2} \mathrm{D}_{\mathrm{t}}^{-}$} & & $91.060^{* \star *}$ \\
\hline & & $(27.123)$ \\
\hline Observações & 1,621 & 1,621 \\
\hline $\mathrm{R}^{2}$ ajustado & 0.022 & 0.028 \\
\hline Estatística F & $10.299^{\pi x *}(\mathrm{df}=4 ; 1617)$ & $8.835^{* \pi x}(\mathrm{df}=6 ; 1615)$ \\
\hline Teste Breusch-Pagan para heterocedasticidade & $6.9902, \mathrm{df}=3$ & $4.453, \mathrm{df}=5$ \\
\hline Teste Durbin-Watson para autocorrelação & 2.8761 & 2.8684 \\
\hline VIF máximo & 2.493604 & 4.411165 \\
\hline
\end{tabular}

Nota: Erro padrão robusto de White entre parêntesis ${ }^{*} p<0.1 ;{ }^{* \pi} p<0.05 ;{ }^{* \star *} p<0.01$

Fonte: Elaboração própria. 
Analisando os resultados obtidos para a equação (1) apresentado na primeira coluna da Tabela 2, observa-se que os coeficientes das variáveis dummy sugerem que a ocorrência de retornos positivos no Ibovespa tem relação negativa com o IVol-BR. Quando observados os retornos, somente o retorno negativo tem relação estatisticamente significativa a $1 \%$ com o IVol-BR. O retorno negativo multiplicado pelo coeficiente também negativo, resulta em impacto positivo no IVol-BR, ou seja, retornos negativos no lbovespa estão associados com aumentos na volatilidade implícita.

A segunda coluna apresenta os resultados da equação (2) que investiga o possível efeito tamanho dos retornos. Aqui, o retorno positivo mostrou relação estatisticamente significativa e negativa com o IVol$\mathrm{BR}$, ou seja, o retorno positivo está associado a uma diminuição na volatilidade implícita, quando controlados os efeitos do tamanho na equação. O efeito tamanho só é significativo para os retornos negativos, apresentando concavidade para cima.

As relações identificadas desafiam a Teoria dos Mercados Eficientes, mas são coerentes com os campos de pesquisa em finanças comportamentais. A relação entre retornos negativos e aumento na volatilidade implícita (coeficiente -1.854) é coerente com os estudos que associam a volatilidade implícita a um índice do medo do investidor. A Teoria dos Prospectos de Kahneman e Tversky (1979) aponta para reações mais intensas do investidor no campo das perdas. Guiso et al. (2018) identifica que a aversão ao risco aumenta após crises (em crises a volatilidade é maior). Segundo Giot (2005), essa maior aversão ao risco leva investidores a venderem ativos indiscriminadamente em momentos de alta volatilidade, o que pressiona os preços para baixo, reduzindo os retornos. Os resultados aqui apresentados são coerentes com essa previsão e com os resultados de Giot (2005) e Li et al. (2019).

Os resultados da Tabela 2 mostram que o modelo estimado é significativo, ou seja, explica parcela relevante da variação dos retornos do IVol-BR, entretanto o $\mathrm{R}^{2}$ ajustado é baixo, o que indica que outras variáveis explicativas podem influenciar o IVol-BR.

Em estudos internacionais como os de Giot (2005), Li et al. (2019) e Rubbaniy et al. (2014), e Cainelli et al. (2021) para o Brasil, a volatilidade implícita e suas relações são investigadas nos diferentes níveis da primeira. Com esse objetivo e também como forma de dar robustez à pesquisa, os modelos acima foram executados nos moldes de regressão quantílica. Na Tabela 3 encontram-se os resultados para a variável dependente retorno do IVol-BR.

Os coeficientes das dummies $\left(D_{t}^{+}\right.$e $\left.D_{t}^{-}\right)$são estatisticamente significativas ao longo de toda a distribuição do IVol-BR, com alguns aspectos interessantes. O sinal é negativo para ambas até a mediana da distribuição e a partir daí positivo. Isso parece mostrar que independente do que ocorra no mercado, a volatilidade tem uma tendência de se manter baixa (alta), que reforça a ideia da memória longa da volatilidade, amplamente estudada (Moraes, Pinto \& Klotzle, 2015). Cabe também pontuar que, apesar dos sinais semelhantes, os coeficientes para $D_{t}^{-}$são maiores que os de $D_{t}^{+}$a partir do percentil 0,90 . Ou seja, volatilidades implícitas extremas estão associadas mais fortemente com a ocorrência de retornos negativos, o que é coerente com as evidências sobre reações assimétricas do investidor apontadas pela literatura de finanças comportamentais (Kahneman e Tversky, 1979; Imas, 2016; Guiso et al., 2018).

O comportamento assimétrico das relações identificadas também se observa na consistente relação estatisticamente significativa e negativa dos retornos negativos com o IVol-BR, e a ausência de significância na relação com os retornos positivos (a exceção dos percentis 0,50 e 0,75 no modelo com retornos quadráticos). Os resultados da regressão quantílica também permitem observar que os coeficientes dos retornos negativos são maiores nos extremos da distribuição do IVol-BR quando comparados ao centro da distribuição. Essas evidências sugerem que o IVol-BR, assim como o VIX na literatura internacional, pode ser interpretado como um índice do medo para o mercado brasileiro. Os resultados são coerentes com Giot (2005) e Rubbaniy et al. (2014) para o mercado americano, e com Li et al. (2019) para o mercado chinês.

Com relação aos efeitos quadráticos dos retornos positivos apontados na Tabela 3 , os resultados da Tabela 4 mostram que essa relação está presente na faixa central de retornos do IVol-BR, e somente para os retornos positivos ao quadrado.

Com a finalidade de avaliar a $\mathrm{H} 2$, foi testado se o índice de volatilidade implícita pode indicar um mercado sobrevendido ou sobrecomprado, considerando a relação entre a variação no índice de volatilidade implícita no tempo $t$ e o retorno futuro do lbovespa, em 1, 5, 20 e 60 dias úteis à frente. Foram analisados separadamente os efeitos dos $30 \%$ maiores e menores retornos do IVol-BR (Dmaior $t_{t}$ e Dmenor $_{t}$ ) e os $40 \%$ centrais da distribuição dos retornos (refletidos no coeficiente da Constante). Os resultados dos modelos estimados, com erro padrão robusto entre parêntesis, são apresentados na Tabela 4. 
Tabela 3

Resultados para o modelo (1) e (2) com regressão quantílica usando IVol-BR

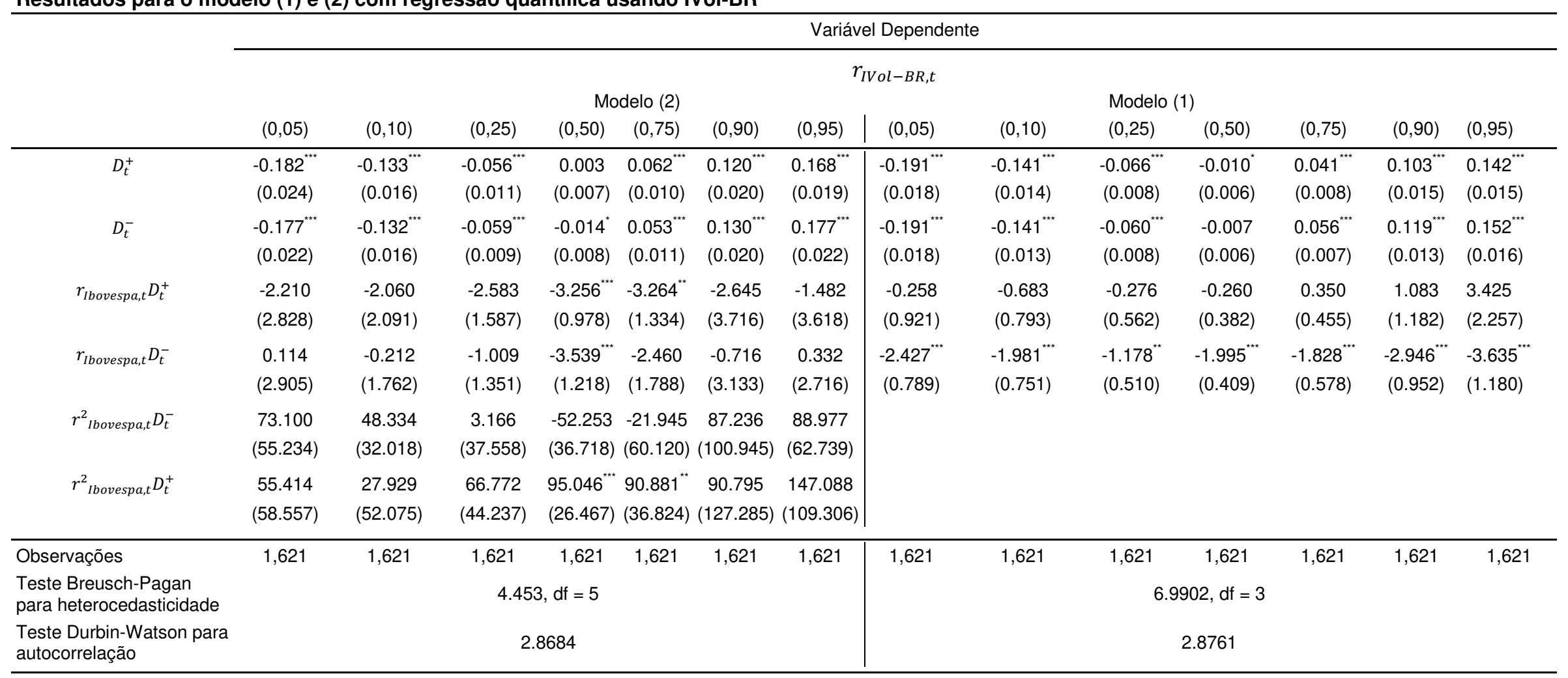

Nota: Erro padrão robusto de White entre parêntesis " $p<0.1 ; " \mathrm{p}<0.05 ; " \mathrm{p}<0.01$

Fonte: Elaboração própria. 


\section{Tabela 4}

Resultados dos modelos (3), (4), (5) e (6) usando IVol-BR

\begin{tabular}{|c|c|c|c|c|}
\hline & \multicolumn{4}{|c|}{ Variável Dependente } \\
\hline Dummy para cluster de observações do IVol-BR & r1d & $r 5 d$ & r20d & r60d \\
\hline & $(1)$ & $(2)$ & $(3)$ & $(4)$ \\
\hline Dmenor $_{t}$ & $0.002^{*}(0.001)$ & $0.001(0.002)$ & $-0.002(0.004)$ & $0.011(0.007)$ \\
\hline $\begin{array}{l}\text { Dmaior }_{t} \\
\text { Constante } \\
\end{array}$ & $\begin{array}{l}0.0002(0.001) \\
-0.0001(0.001)\end{array}$ & $\begin{array}{l}-0.0002(0.002) \\
0.001(0.002)\end{array}$ & $\begin{array}{l}-0.004(0.004) \\
0.009^{\star * *}(0.003)\end{array}$ & $\begin{array}{l}0.007(0.007) \\
0.013^{* *}(0.005)\end{array}$ \\
\hline Observações & 1,369 & 1,369 & 1,369 & 1,369 \\
\hline $\mathrm{R}^{2}$ ajustado & 0.001 & -0.001 & 0.001 & 0.0004 \\
\hline Estatística F (df = 22; 1367) & 1.879 & 0.295 & 0.365 & 1.307 \\
\hline Teste Breusch-Pagan para heterocedasticidade & $0.18333, \mathrm{df}=2$ & $3.0159, \mathrm{df}=2$ & $0.073493, \mathrm{df}=2$ & $0.67758, \mathrm{df}=2$ \\
\hline Teste Durbin-Watson para autocorrelação & 1.9684 & 0.46709 & 0.11591 & 0.044511 \\
\hline VIF máximo & & & 38542 & \\
\hline
\end{tabular}

Nota: Erro padrão de White entre parêntesis

$p<0.1 ; p<0.05 ;{ }^{* * *} p<0.01$

Fonte: Elaboração própria. 
Os resultados para os extremos da distribuição do IVol-BR não são estatisticamente significativos, observando-se sinal marginalmente positivo apenas para a relação entre os $30 \%$ menores retornos e o retorno do lbovespa um dia a frente. Nenhum dos coeficientes analisados para as observações no cluster dos $30 \%$ maiores apresentou relação estatisticamente significativa com retornos futuros do Ibovespa. É interessante ressaltar a relação estatisticamente significativa da constante $\left(\beta_{0}\right)$ com os retornos futuros de 20 e 60 dias do lbovespa. Ou seja, variações do IVol-BR classificados nos $40 \%$ centrais da distribuição tem relação positiva com os retornos de 20 e 60 dias. Observa-se ainda que o coeficiente é maior na relação com retorno futuro de 60 dias $(0,013)$ do que com retorno futuro de 20 dias $(0,009)$. Ou seja, os níveis médios de volatilidade são mais relevantes para explicar os retornos futuros do que as volatilidades extremas.

Os resultados aqui encontrados contrastam com os de Giot (2005) e Rubbaniy et al. (2014), e com os de Cainelli et al. (2021), uma vez que os autores encontram relações significativas para volatilidades implícitas mais altas. Entretanto, as relações significativas para os prazos maiores (20 e 60 dias) são coerentes com os estudos mencionados.

A investigação das relações do IVol-BR com retornos futuros, ou seja, a identificação de um possível hiato entre a ocorrência do IVol-BR e a resposta do lbovespa pode servir para estruturação de posições de mercado, objetivando retornos extraordinários. Os resultados, que podem representar uma contestação da Hipótese dos Mercados Eficientes, sugerem potencial para esse tipo de análise para os prazos mais longos, assim como nos estudos internacionais mencionados.

\section{Análise de Robustez}

A volatilidade foi estimada pelo modelo GARCH $(1,1)$, que substituiu o IVol-BR nas análises, de modo a testar a robustez dos modelos. Para testar a $\mathrm{H} 1$, utilizou-se a volatilidade estimada por GARCH como proxy para a variável dependente a ser utilizada na equação (1). Os resultados encontram-se na Tabela 5.

\section{Tabela 5}

Resultados do modelo das equações (1) e (2) para GARCH $(1,1)$

\begin{tabular}{|c|c|c|}
\hline & \multicolumn{2}{|c|}{ Variável dependente } \\
\hline & \multicolumn{2}{|c|}{$r_{G A R C H}$} \\
\hline & (1) & (2) \\
\hline \multirow[t]{2}{*}{$D_{t}^{+}$} & $-0.060^{m * x}$ & $-0.048^{\mathrm{mm}}$ \\
\hline & $(0.002)$ & $(0.003)$ \\
\hline \multirow[t]{2}{*}{$D_{t}^{-}$} & $-0.060^{\pi x+}$ & $-0.043^{x \times x}$ \\
\hline & $(0.002)$ & $(0.003)$ \\
\hline \multirow[t]{2}{*}{$r_{\text {Ibovespa }, t} D_{t}^{+}$} & $5.382^{* * * *}$ & $3.135^{* * *}$ \\
\hline & $(0.160)$ & $(0.407)$ \\
\hline \multirow[t]{2}{*}{$r_{\text {Ibovespa,t }} D_{t}^{-}$} & $-5.214^{* * * *}$ & $-1.713^{* * * *}$ \\
\hline & $(0.174)$ & $(0.472)$ \\
\hline \multirow[t]{2}{*}{$r_{\text {Ibovespa, }}^{2} D_{t}^{+}$} & & $108.017^{* * *}$ \\
\hline & & (13.592) \\
\hline \multirow[t]{2}{*}{$r_{\text {Ibovespa,t }}^{2} D_{t}^{-}$} & & $61.266^{* * *}$ \\
\hline & & $(10.244)$ \\
\hline Observações & 1,621 & 1,621 \\
\hline$R^{2}$ ajustado & 0.556 & 0.582 \\
\hline Estatística $F$ & $509.395^{\circ * *}(d f=4 ; 1617)$ & $376.439^{n \times x}(d f=6 ; 1615)$ \\
\hline Teste Breusch-Pagan para heterocedasticidade & $31.327, d f=3$ & $62.58, d f=5$ \\
\hline Teste Durbin-Watson para autocorrelação & 1.6012 & 1.5512 \\
\hline VIF máximo & 2.493604 & 4.196658 \\
\hline
\end{tabular}

Nota: Erro padrão robusto de White entre parêntesis $\quad p<0.1 ; " p<0.05 ; " \mathrm{p}<<0.01$

Fonte: Elaboração própria. 
Observa-se que todos os coeficientes possuem significância estatística a 0,01 , ou seja, retornos positivos ou negativos do lbovespa influenciam a volatilidade. Também se observa que não existe grande variação nos valores dos coeficientes, independente do sinal. Neste caso, quando avaliada pelo modelo GARHC $(1,1)$, os resultados não foram de encontro ao obtido por Giot (2005) e também não vão ao encontro dos resultados obtidos quando utilizada a volatilidade medida pelo IVol-BR. Quando observados 0 efeito quadrático, para a variável do retorno da volatilidade medida por GARCH, também se vê a concavidade voltada para cima.

Nota-se significância estatística em todos os coeficientes, o que pode ser explicado pelo fato de a volatilidade implícita estimada pelo modelo $\operatorname{GARCH}(1,1)$ utilizar dados históricos da própria volatilidade. A Tabela 6 apresenta o resultado para as equações (1) e (2) quando utilizada a volatilidade estimada pelo modelo GARCH $(1,1)$ e o modelo de regressão quantílica.

Para este conjunto de regressões, o resultado se dá de maneira razoavelmente diferente: o efeito quadrático possui significância estatística a partir do Quantil 0,25 quando interagido com a dummy de retorno negativo do Ibovespa, e a partir do Quantil 0,10 quando interagido com a dummy de retorno positivo do lbovespa.

Ademais, para o modelo de equação (1), o impacto nos retornos da volatilidade medida por GARCH foi negativa em todos os Quantis para todas as variáveis explicativas, à exceção da interação da dummy de retorno positivo com o retorno do Ibovespa, a qual obteve significância estatística em todos os Quantis e com efeito positivo. Também se observa que, quando interagido com a dummy de retorno do lbovespa, positivo ou negativo, os coeficientes têm maior efeito nos Quantis superiores, acima de 0.75 .

Quando utilizado o cluster para a proxy de volatilidade estimada pelo modelo $\mathrm{GARCH}$, os resultados das regressões das equações (3), (4), (5) e (6) contra os retornos futuros do Ibovespa são os dispostos na Tabela 7. 
Tabela 6

Resultados para o modelo (1) e (2) com regressão quantílica usando GARCH $(1,1)$

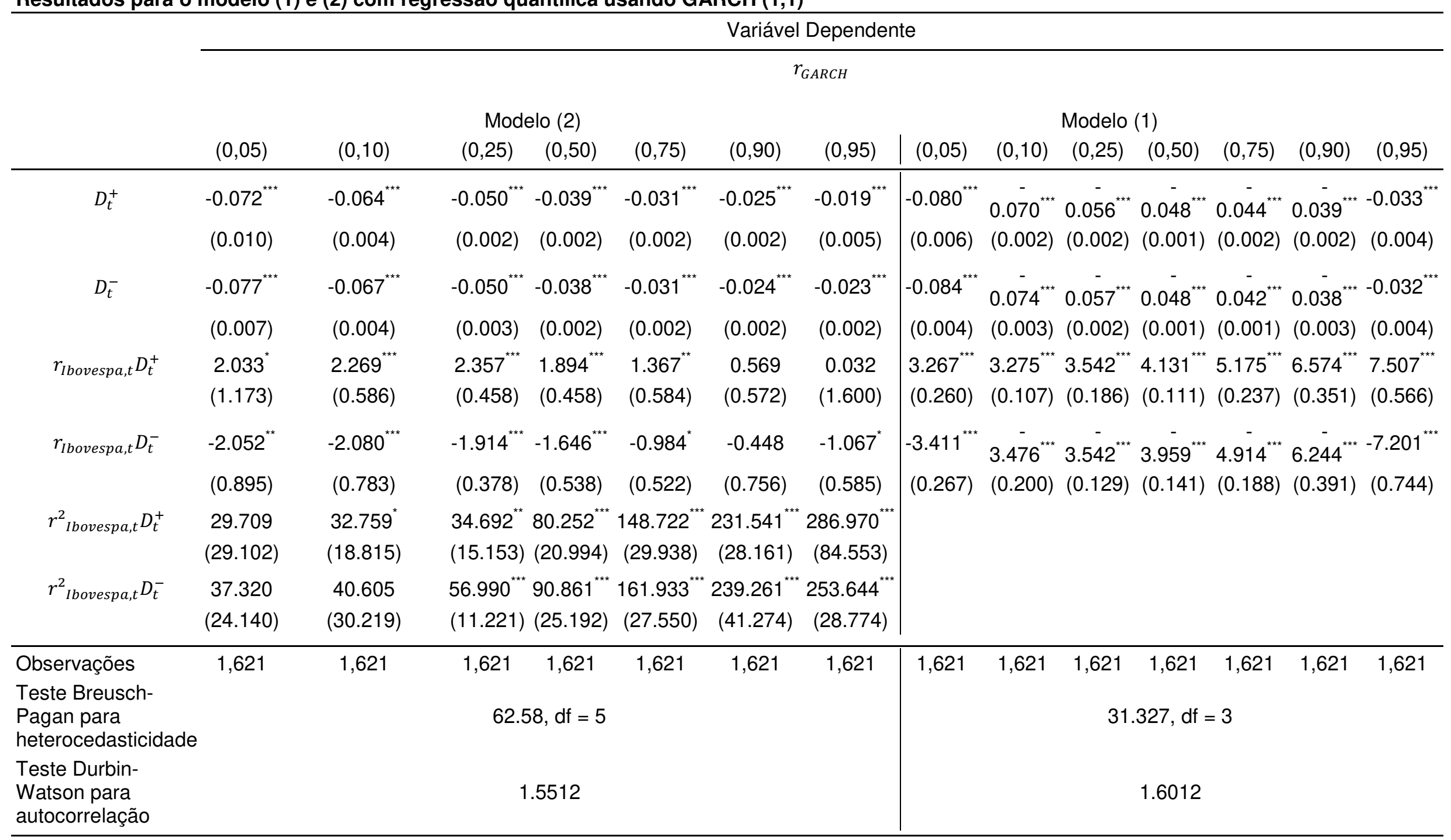

Nota: Erro padrão robusto de White entre parêntesis $\quad p<0.1 ; " p<0.05 ;{ }^{* * *} p<0.01$

Fonte: Elaboração própria. 
Tabela 7

Resultados dos modelos (3), (4), (5) e (6) usando GARCH (1,1) Dummy para cluster de
observações GARCH

\begin{tabular}{l}
\multicolumn{1}{c}{$\begin{array}{c}\text { Dmenor }_{t} \\
\text { Dmaior } \\
\text { Constante }\end{array}$} \\
\hline Observações \\
$\mathrm{R}^{2}$ ajustado \\
Estatística $\mathrm{F}(\mathrm{df}=22 ; 1367)$ \\
Teste Breusch-Pagan para \\
heterocedasticidade \\
Teste Durbin-Watson para \\
autocorrelação \\
VIF máximo
\end{tabular}

\begin{tabular}{llll}
\multicolumn{4}{c}{ Variável Dependente } \\
\hline$r 1 d$ & $r 5 d$ & r20d & r60d
\end{tabular}

(1)

(2)

\begin{tabular}{llll}
$-0.0002(0.001)$ & $-0.002(0.002)$ & $0.002(0.004)$ & $0.014^{\star *}(0.007)$ \\
$0.001(0.001)$ & $0.001(0.002)$ & $-0.0004(0.004)$ & $0.004(0.007)$ \\
$0.0003(0.001)$ & $0.002(0.001)$ & $0.006^{\star *}(0.003)$ & $0.013^{\star * *}(0.005)$ \\
\hline 1,369 & 1,369 & 1,369 & 1,369 \\
-0.0003 & -0.0003 & -0.001 & 0.002 \\
0.820 & 0.791 & 0.224 & 2.238
\end{tabular}

2.6656, $d f=2 \quad 1.2809, d f=2 \quad 1.5279, d f=2 \quad 0.11874, d f=2$

1.9607

0.46878

0.1155

0.047454

Nota: Erro padrão robusto de White entre parêntesis. ${ }^{*} \mathrm{p}<0.1 ;{ }^{* *} \mathrm{p}<0.05 ;{ }^{* * *} \mathrm{p}<0.01$

Fonte: elaboração própria.

Observa-se que, mesmo utilizando outra proxy para a volatilidade, os resultados foram semelhantes aos obtidos quando utilizado os retornos do IVol-BR, à exceção do $\beta_{1}$, que para análise da estimação por GARCH apresentou significância estatística para os retornos de 60 dias, quando para a análise pelo IVolBR apresentou significância estatística para os retornos de 5 dias, ambas positivas.

Com relação aos $40 \%$ centrais da distribuição das variações da volatilidade estimada pelo GARCH, os resultados são semelhantes aos obtidos com o IVol-BR. Nota-se relação estatisticamente significativa e positiva com retornos do lbovespa de 20 e 60 dias a frente, sendo o coeficiente maior para o retorno de 60 dias. Este resultado sugere que, para níveis medianos de volatilidade, é possível observar relação entre medidas de volatilidade e retornos futuros mais longos.

\section{Considerações Finais}

O objetivo deste trabalho foi verificar se existe relação entre a volatilidade implícita, medida pelo IVol-BR, e os retornos do lbovespa. Essa relação é investigada de duas formas, tanto com retornos contemporâneos quanto com retornos futuros de 1, 5, 20 e 60 dias úteis. A análise da relação contemporânea é importante como validação do IVol-BR como medida de volatilidade implícita para o mercado brasileiro. Os resultados também podem ser indicativos para movimentos de entrada ou saída de posições na bolsa brasileira.

Os resultados encontrados desafiam a TME e apresentam evidências em linha com as finanças comportamentais. $\mathrm{Na}$ análise das relações contemporâneas entre retornos do lbovespa e o IVol-BR a relação é negativa e mais intensa quando o retorno do lbovespa é negativo. Estes resultados corroboram com os achados de Giot (2005), que concluiu que retornos negativos no índice de ações são associados a maiores mudanças relativas na volatilidade. Quando analisada a relação entre o lbovespa e o IVol-BR, incluídos os retornos quadráticos do índice de mercado, observou-se que o efeito tamanho só é significativo para os retornos negativos, apresentando concavidade para cima.

Os resultados sugerem que, assim como demonstrado em finanças comportamentais, o investidor reage mais exacerbadamente a notícias ruins (retornos negativos) do que a notícias boas (retornos positivos), indicando que o investidor não é, necessariamente, racional (Kahneman e Tversky, 1979; Guiso et al., 2018).

A regressão quantílica permitiu observar que os coeficientes dos retornos negativos são maiores nos extremos da distribuição do IVol-BR. Essas evidências sugerem que o IVol-BR pode ser interpretado como um índice do medo para o mercado brasileiro (Giot, 2005; Rubbaniy et al., 2014; Li et al., 2019).

$\mathrm{Na}$ análise da relação com os retornos futuros do lbovespa, foi observado que, para níveis médios de volatilidade, há relação positiva com os retornos futuros de 20 e 60 dias, evidenciando a existência de memória longa na volatilidade do mercado brasileiro. Os resultados estão em linha com os internacionais e nacionais com relação à relação com prazos mais longos, mas contradizem as relações sugeridas nos estudos para as volatilidades mais altas (Giot, 2005; Rubbaniy et al., 2014; Cainelli et al., 2021).

De modo a dar maior robustez às análises, também foi feita estimação da volatilidade pelo modelo GARCH $(1,1)$ e esta foi utilizada como proxy da volatilidade implícita, alternativa ao IVol-BR. Os coeficientes encontrados tiveram os mesmos sinais que os encontrados para o IVol-BR. 
Foi apresentada uma nova forma de entender a relação risco e retorno no mercado brasileiro, o que pode auxiliar gestores no momento de estruturar a metodologia de investimento, sendo, também, aplicável ao mundo real. A pesquisa também acrescenta à literatura ao utilizar-se de uma proxy pouco aplicada, o IVol-BR, comprando-a a proxies para a volatilidade, e utilizando diferentes métodos de estimação.

Pesquisas futuras podem se debruçar sobre que reação eventos ou notícias podem desencadear na volatilidade implícita, além de estudos que buscam verificar resultados obtidos em portfólios usando estratégias construídas com base no timing extraído da análise do comportamento da volatilidade implícita e do índice lbovespa.

\section{Referências}

Angrist, J. D., \& Pischke, J.-S. (2009). Mostly Harmless Econometrics: An Empiricist's Companion. Princeton University Press.

Astorino, E., Chague, F., Giovannetti, B. C., \& Silva, M. E. (2017). Variance Premium and Implied Volatility in a Low-Liquidity Option Market. Revista Brasileira de Economia, 71(1), 3-28. https://doi.org/10.5935/0034$\underline{7140.20170001}$

Bagchi, D. (2012). Cross-sectional analysis of emerging market volatility index (India VIX) with portfolio returns. International Journal of Emerging Markets, 7(4), 383-396.

https://doi.org/10.1108/17468801211264306

Banerjee, P. S., Doran, J. S., \& Peterson, D. R. (2007). Implied volatility and future portfolio returns. Journal of Banking \& Finance, 31(10), 3183-3199. http://dx.doi.org/10.1016/j.jbankfin.2006.12.007

Bodie, Z., Kane, A., \& Marcus, A. J. (2015). Investimentos. AMGH editora

Cainelli, P. V., Pinto, A. C. F., Klötzle, M. C. (2021). Estudo sobre a relação entre o IVol-BR e os retornos futuros do mercado acionário brasileiro. Revista Brasileira de Contabilidade \& Finanças - USP, São Paulo, v. 32, n. 86, p. 255-272, maio/ago. 2021. https://doi.org/10.1590/1808-057x202009890

Campbell, J. Y., \& Shiller, R. J. (1998). Valuation Ratios and the Long-Run Stock Market Outlook. The Journal of Portfolio Management, 24(2), 11-26. https://doi.org/10.3905/ipm.24.2.11

Duppati, G., Kumar, A. S., Scrimgeour, F., \& Li, L. (2017). Long memory volatility in Asian stock markets. Pacific Accounting Review, 29(3), 423-442. https://doi.org/10.1108/PAR-02-2016-0009

Engle, R. F. (1982). Autoregressive Conditional Heteroscedasticity with Estimates of the Variance of United Kingdom Inflation. Econometrica, 50(4), 987-1007. https://doi.org/10.2307/1912773

Fama, E. F. (1970). Efficient Capital Markets: A Review of Theory and Empirical Work. The Journal of Finance, 25(2), 383-417. https://doi.org/10.2307/2325486

Friedman, M., \& Savage, L. J. (1948). The Utility Analysis of Choices Involving Risk. Journal of Political Economy, 56(4), 279-304. https://doi.org/10.1086/256692

Giot, P. (2005). Relationships Between Implied Volatility Indexes and Stock Index Returns. The Journal of Portfolio Management, 31(3), 92-100. https://doi.org/10.3905/jpm.2005.500363

Guiso, L., Sapienza, P., \& Zingales, L. (2018). Time varying risk aversion. Journal of Financial Economics, 128(3), 403-421. https://doi.org/10.1016/j.jfineco.2018.02.007

Gujarati, D. N., \& Porter, D. C. (2011). Econometria Básica. AMGH editora.

Imas, A. (2016). The Realization Effect: Risk-Taking After Realized Versus Paper Losses. American Economic Review, 106(8), 2086-2109. https://doi.org/10.1257/aer.20140386

Kahneman, D., \& Tversky, A. (1979). Prospect Theory: An Analysis of Decision under Risk. Econometrica, 47(2), 263-291. https://doi.org/10.2307/1914185

Lee, Y. - H. (2015). Does the US Fear Gauge Impact on the Investor Fear Gauge in the Emerging Markets? Journal of Emerging Market Finance, 14(3), 197-209. https://doi.org/10.1177\%2F0972652715601909 
Li, J., Yu, X., \& Luo, X. (2019). Volatility Index and the return-volatility Relation: Intraday Evidence from Chinese Options Market. Journal of Futures Markets, 39(11), 1348-1359. https://doi.org/10.1002/fut.22012

Lo, A. W. (2004). The Adaptive Markets Hypothesis. The Journal of Portfolio Management, 30(5), 15-29. https://doi.org/10.3905/jpm.2004.442611

Markowitz, H. (1952). Portfolio Selection. The Journal of Finance, 7(1), 77-91. https://doi.org/10.1111/j.15406261.1952.tb01525.x

Mello, A. R. A. F. (2009). Volatilidade implícita das opções de ações: uma análise sobre a capacidade de previsão do mercado sobre a volatilidade futura. Dissertação de Mestrado, Fundação Getúlio Vargas, São Paulo, SP, Brasil.

Moraes, A. S. M. D., Pinto, A. C. F., \& Klotzle, M. C. (2015). Previsão de value-at-risk e expected shortfall para mercados emergentes usando modelos FIGARCH. Brazilian Review of Finance, 13(3), 394-437-394437. https://doi.org/10.12660/rbfin.v13n3.2015.53080

Pinho, F. M., Camargos, M. A., \& Figueiredo, J. M. (2017). Uma Revisão da Literatura sobre Modelos de Volatilidade em Estudos Brasileiros de 2000 a 2014. Revista de Administração FACES Journal, 16(1), 9-28. http://dx.doi.org/10.21714/1984-6975FACES2017V16N1ART3213

Rubbaniy, G., Asmerom, R., Rizvi, S. K. A., \& Naqvi, B. (2014). Do fear indices help predict stock returns? Quantitative Finance, 14(5), 831-847. https://doi.org/10.1080/14697688.2014.884722

Smales, L. A. (2016). Risk-on/Risk-off: Financial market response to investor fear. Finance Research Letters, 17, 125-134. https://doi.org/10.1016/j.frl.2016.03.010

Taleb, N. N. (2010). The Black Swan: the impact of the highly improbable. Random House Trade editora.

Thurner, S., Farmer, J. D., \& Geanakoplos, J. (2012). Leverage causes fat tails and clustered volatility. Quantitative Finance, 12(5), 695-707. https://doi.org/10.1080/14697688.2012.674301

Vicente, J. V. M., \& Guedes, T. S. (2010). A Volatilidade implícita contém informações sobre a volatilidade futura? Evidências do mercado de opções de ações da Petrobras. Brazilian Business Review, 7(1), 48-65. http://dx.doi.org/10.15728/bbr.2010.7.1.3

Whaley, R. E. (2000). The Investor Fear Gauge. The Journal of Portfolio Management, 26(3), 12-17. https://doi.org/10.3905/ipm.2000.319728

\section{NOTAS}

\section{AGRADECIMENTOS}

Não se aplica.

\section{CONTRIBUIÇÃO DE AUTORIA}

Concepção e elaboração do manuscrito: A. F. F. Martins, P. M. Bortolon, V. M. Maia

Coleta de dados: A. F. F. Martins

Análise de dados: A. F. F. Martins, P. M. Bortolon. V. M. Maia

Discussão dos resultados: A. F. F. Martins, P. M. Bortolon. V. M. Maia

Revisão e aprovação: A. F. F. Martins, P. M. Bortolon. V. M. Maia

\section{CONJUNTO DE DADOS DE PESQUISA}

O conjunto de dados que dá suporte aos resultados deste estudo não está disponível publicamente.

\section{FINANCIAMENTO}

Não se aplica.

\section{CONSENTIMENTO DE USO DE IMAGEM}

Não se aplica.

\section{APROVAÇÃO DE COMITÊ DE ÉTICA EM PESQUISA}

Não se aplica.

\section{CONFLITO DE INTERESSES}


Não se aplica.

\section{LICENÇA DE USO}

Os Direitos Autorais para artigos publicados neste periódico são do autor, com direitos de primeira publicação para a Revista. Em virtude de aparecerem nesta Revista de acesso público, os artigos são de uso gratuito, com atribuições próprias, em aplicações educacionais, de exercício profissional e para gestão pública. A Revista adotou a licença Creative Commons Atribuição 4.0 Internacional - CC BY NC ND. Esta licença permite acessar, baixar (download), copiar, imprimir, compartilhar, reutilizar e distribuir os artigos desde que com a citação da fonte, atribuindo os devidos créditos de autoria. Nesses casos, nenhuma permissão é necessária por parte dos autores ou dos editores. Autores têm autorização para assumir contratos adicionais separadamente, para distribuição não-exclusiva da versão do trabalho publicada nesta revista (ex.: publicar em repositório institucional ou um capítulo de livro).

\section{PUBLISHER}

Universidade Federal de Santa Catarina. Curso de Ciências Contábeis e Programa de Pós-graduação em Contabilidade. Publicação no Portal de Periódicos UFSC. As ideias expressadas neste artigo são de responsabilidade de seus autores, não representando, necessariamente, a opinião dos editores ou da universidade.

\section{EDITORES}

Carlos Eduardo Facin Lavarda e Suliani Rover

\section{HISTÓRICO}

Recebido em: 16/10/2020 - Revisado por pares em: 12/05/2021 - Reformulado em: 30/07/2021 Recomendado para publicação em: 02/08/2021 - Publicado em: 04/12/2021

\footnotetext{
${ }^{\mathrm{i}}$ Termo do mercado financeiro para se referir a um movimento coletivo de busca por ativos mais seguros, observado, geralmente, em momentos de crise e incerteza econômica.

ii Conceito criado por Nassin Taleb para explicar momentos de crise ou eventos raros de grande impacto, os quais não são passíveis de previsão.

iii Para a completa descrição do cálculo do VIX ver Cboe: https://www.cboe.com/micro/vix/vixwhite.pdf

${ }^{\text {iv }}$ Por exemplo, $r_{5} d_{t}$ é calculado da seguinte forma: $\ln \left(P_{t+5}\right)-\ln \left(P_{t}\right)$, e é o retorno prospectivo relativo ao nível do IVol-BR observado no tempo $t$.

${ }^{v}$ A tabela de correlações é omitida por questões de espaço, mas está disponível com os autores para apresentação, se solicitada.
} 